\title{
Acute renal failure in association with cosmetic suction lipectomy
}

\author{
Geoffrey E. Rose
}

King's College Hospital, London SE5 9RS, UK

\begin{abstract}
Summary: A case of severe non-oliguric acute renal failure following cosmetic suction lipectomy in a 33 year old woman is described. The renal failure, although requiring emergency treatment, resolved spontaneously with only negligible residual impairment of renal function. An aetiology involving rhabdomyolysis and myoglobinuria is proposed and other mechanisms are discussed.
\end{abstract}

\section{Introduction}

Efforts to reduce scar size after cosmetic lipectomy have led, in recent years, to the development of the technique of suction-curettage lipectomy (Kesselring \& Meyer, 1978; Illouz, 1980; Teimourian \& Fisher, 1980). A unique case of severe acute non-oliguric renal failure, occurring in association with this procedure, is described and mechanisms postulated.

\section{Case report}

A 33 year old woman was admitted with a history of increasing vomiting for 1 week following suctioncurrettage lipectomy performed abroad. In addition to anorexia and general weakness, she had also noticed exertional dyspnoea and palpitations.

On examination, she was anaemic, not dehydrated (she weighed $64.5 \mathrm{~kg}$ on admission and $62.0 \mathrm{~kg}$ on discharge), pulse rate $88 / \mathrm{min}$, blood pressure $140 /$ $90 \mathrm{~mm} \mathrm{Hg}$. There were signs of pulmonary oedema and marked bruising of the areas treated, namely her infra-umbilical abdominal wall, her thighs and her arms (Figure 1).

Urine analysis demonstrated proteinuria, but no urinary casts or fat globules on microscopy. Her haemoglobin was $7.6 \mathrm{~g} / \mathrm{dl}$, white cell count $9.4 \times 10^{9} / 1$, erythrocyte sedimentation rate (ESR) $44 \mathrm{~mm}$ in first hour, serum sodium $127 \mathrm{mmol} / 1$, potassium $7.0 \mathrm{mmol} / 1$, bicarbonate $16 \mathrm{mmol} / \mathrm{l}$, urea $93 \mathrm{mmol} / \mathrm{l}$, creatinine $1565 \mu \mathrm{mol} / 1$, glucose $5.4 \mathrm{mmol} / \mathrm{l}$, calcium (adjusted for low albumin) $2.13 \mathrm{mmol} / 1$, inorganic phosphates

Correspondence and present address: G.E. Rose, B.Sc., M.B., B.S., M.R.C.P., Moorfields Eye Hospital, City Road, London EC1V 2PD, UK.

Accepted: 21 June 1985

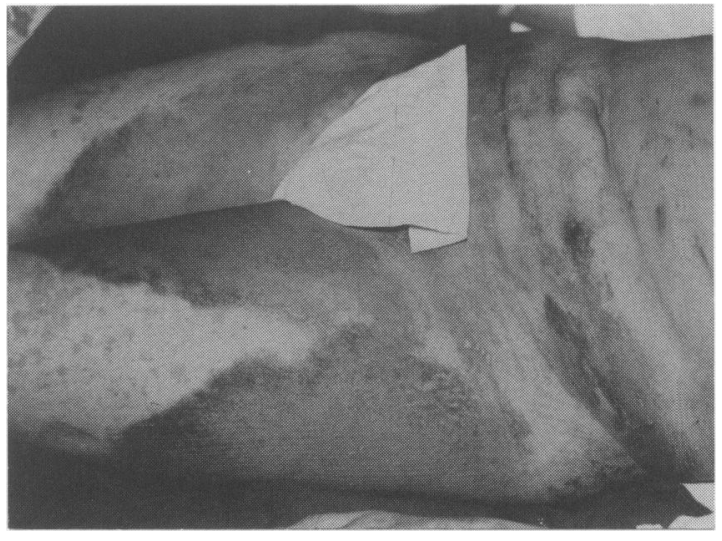

Figure 1 View of patient 2 weeks after surgery.

$3.72 \mathrm{mmol} / 1$ and uric acid $1.05 \mathrm{mmol} / 1$. Serum amylase was normal. Liver function tests were normal with the exception of a low albumin $(26 \mathrm{~g} / \mathrm{l})$ and serum creatine kinase. Chest $\mathrm{X}$-ray showed pulmonary plethora and a collapsed left lower lobe; electrocardiogram and renal ultrasound were normal

Daily haemodialysis was performed on the first 4 days of admission. Resolution of the pulmonary vascular plethora and the lower lobe collapse occurred rapidly.

From the sixth day of admission, a spontaneous resolution of the renal failure was evident (Figure 2). Throughout admission, urine output was greater than $800 \mathrm{ml} / \mathrm{d}$.

Two years after the surgery the patient remains well, with normal blood chemistry and renal function.

The Fellowship of Postgraduate Medicine, 1985 


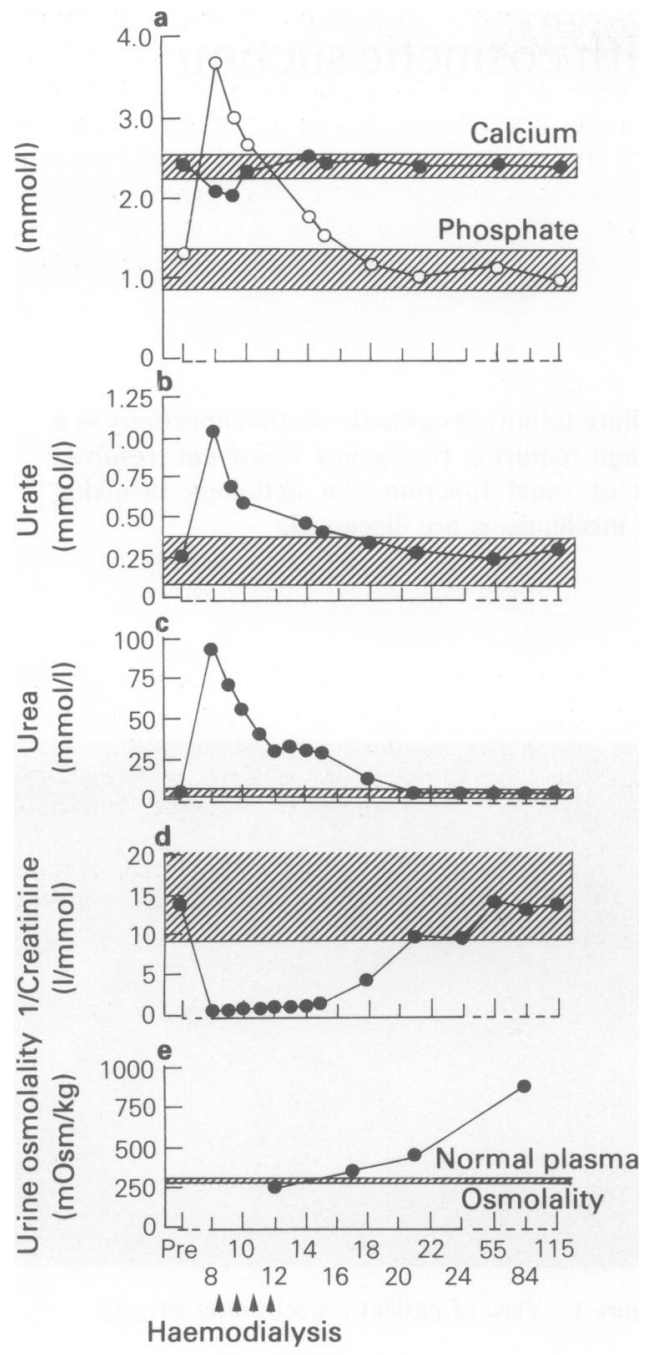

Time (d) after surgery

Figure 2 Biochemical profile of case report: (a) Serum calcium (O), inorganic phosphates (O), (b) uric acid; (c) urea; (d) serum creatinine reciprocal and (e) early morning urinary osmolality (after approximately $10 \mathrm{~h}$ of dehydration). Cross-hatched areas represent normal ranges except where otherwise indicated; arrows indicate sessions of haemodialysis.

\section{Surgical procedure}

Twelve drugs [ethamsylate, extranase (bromelains* -

* This preparation was not thought to be implicated in the patient's acute renal failure due to the time course over which it was given, its inactivity as a proteolytic agent given orally and the absence of previous evidence of any nephrotoxicity.
Rover Pharmaceuticals, Essex), atropine, droperidol, phenoperidine, thiopentone, flunitrazepam, suxamethonium, pancuronium, pancreatic proteases, hyaluronidase and Haemaccel] were administered before or during the operative procedure, which lasted for approximately $2 \frac{1}{2} \mathrm{~h}$, with the patient mainly in the prone position under general anaesthesia. To facilitate aspiration of fat, hyaluronidase was injected subdermally into areas to be treated (Illouz, 1980). Our patient recalls having been told that she had an 'unusual' degree of bleeding and bruising during operation, but post-operative drainage from the operative sites was minimal. No hypotensive episode was recorded during or after anaesthesia, although, whilst receiving blood transfusion in the postoperative period, she had a brief rigor. Vomiting started after the operation and she noticed slight darkening of her urine for a few days, but no oliguria.

\section{Discussion}

The renal failure in this patient was acute, probably non-oliguric, with the biochemical changes of mixed glomerular and tubular impairment (Figure 2). Although not nephrotic during admission, the low serum albumin with normal hepatic function implies renah protein loss before admission. Renal biopsy was noto indicated.

The renal failure in the case described strongly resembles that caused by myoglobinuria in several characteristics - namely, the extreme hyperuricaemia, the gross hyperphosphataemia and the rapid rate of rise of serum creatinine and serum potassium (Koffler et al., 1976; Grossman et al., 1974) although serum creatine kinase and aspartate transaminase concentrations were normal and no myoglobinuria was detected in the earliest specimens collected (8 days after surgery). Rhabdomyolysis may have followed prolonged pressure on skeletal muscle disrupted by curettage, and hyaluronidase might have caused myoglobinaemia.

The patient was not recorded to be hypotensive during or after surgery. Although rigors, a slight darkening of the patient's urine and anaemia might indicate a haemolytic episode, the patient did not experience the characteristic symptoms of complement-mediated haemolysis (Mollison, 1979); in addition, a normal blood film and a negative Coombs' test on admission would be unusual 1 week after an incompatible blood transfusion and the patient did not develop any atypical antibodies to blood group antigens. It is possible that haemolysed, effete blood was transfused; if the deterioration was caused by bacterial contamination, however, a post-transfusion septicaemia necessitating treatment would have been expected. 
Other causes of renal failure may be discounted in the case reported. During admission, no signs of an active nephritis developed and anti-streptolysin 0 titres remained low. Anti-nuclear, anti-mitochondrial and anti-smooth muscle antibody titres were negative and concentrations of the immunoglobulins and the $\mathrm{C} 3$ and $\mathrm{C} 4$ components of complement were normal. Neither radiographic nor clinical signs of fat emboli or vasculitic microinfarctions appeared during the illness. None of the drugs used before or during the procedure have been recorded as causing renal failure. With the exception of a brief postoperative rigor, there were no symptoms compatible with septicaemia or disseminated intravascular coagulation and blood cultures taken on admission were sterile.

\section{References}

GROSSMAN, R.A., HAMILTON, R.W., MORSE, B.M., PENN \& A.S. GOLDBERG, M. (1974). Non-traumatic rhabdomyolysis and acute renal failure. New England Journal of Medicine, 291, 807.

ILLOUZ, Y.G. (1980). Une nouvelle technique pour les lipodystrophies localisees. Revue de Chirurgie esthétique de langue française, 19, 3.

KESSELRING, U.K. \& MEYER, R. (1978). Suction curette for removal of excessive local deposits of subcutaneous fat. Plastic and Reconstructive Surgery, 62, 305.
Having been previously clinically and biochemically well, the development of such severe renal failure in this patient is almost certainly attributable to the operative procedure. Rhabdomyolysis, either suxamethonium-induced or produced by a combination of surgical trauma, enzyme therapy and muscle compression, was the probable mechanism, although transfusion of haemolysed blood remains a possibility.

\section{Acknowledgement}

I wish to thank Dr J.F. Costello for permission to publish details of this case under his care and $\mathrm{Mr}$ Colin Clements for photographic assistance.

KOFFLER, A., FRIEDLER, R.M. \& MASSRY, S.G. (1976). Acute renal failure due to non-traumatic rhabdomyolysis. Annals of Internal Medicine, 85, 23.

MOLLISON, P.L. (1979). In Blood Transfusion in Clinical Medicine, 6th Edition. Blackwell Scientific Publications: Oxford.

TEIMOURIAN, B. \& FISHER, J.B. (1980). Suction curette to remove excess fat for body contouring. Plastic and Reconstructive Surgery, 68, 50. 